Mariusz Pandura

Uniwersytet Wrocławski, Wrocław

ORCID: 0000-0001-5875-2705

e-mail: mariusz.pandura@uni.wroc.pl

\title{
Protokoty seminarium arystotelesowskiego Romana Witolda Ingardena z roku akademickiego 1937/1938
}

Protokoły z seminarium arystotelesowskiego Romana Witolda Ingardena z roku 1937/1938 powstały we Lwowie. Przetrwały w mieście nad Pełtwią II wojnę światową. W 1945 roku zostały wywiezione z miasta i podążyły za filozofem, który wówczas szukał swojego miejsca na jednej z polskich uczelni w Krakowie, a także we Wrocławiu. W okresie powojennym były przechowywane przez Ingardena w jego mieszkaniu przy ulicy Biskupiej $14 \mathrm{w}$ Krakowie. Po śmierci fenomenologa zostały przekazane przez rodzinę do ówczesnego Oddziału Archiwum Polskiej Akademii Nauk w Krakowie w jednej z transz, do których doszło w latach 1973-1992 ${ }^{1}$. Obecnie sa przechowywane w Archiwum Nauki Polskiej Akademii Nauk i Polskiej Akademii Umiejętności w Krakowie w zbiorze K-III 26: Roman Ingarden, w dwuczęściowej jednostce 65, jako wydzielony podzbiór: 1937/38. W bezpośrednim związku z protokołami seminarium arystotelesowskiego stoi znajdujący się $\mathrm{w}$ tej samej jednostce spis uczestników tego seminarium, jak również wypisy z przeprowadzonej w Bibliotece Uniwersyteckiej we Lwowie kwerendy bibliograficznej dotyczącej Metafizyki Arystotelesa. Z materiałami seminarium są także związane tematycznie archiwalia przechowywane $\mathrm{w}$ tym samym

1 Zob. Rita Majkowska, „Roman Ingarden”, w: Przewodnik po zasobie Archiwum $P A N$, red. Hanna Krajewska, Alicja Kulecka (Warszawa: Wydawnictwo Retro-Art, 1999), 368-369. 
zbiorze w jednostce 84, podzbiorze 11 (listy Konstantego Michalskiego do Romana Witolda Ingardena).

Protokoły z seminarium arystotelesowskiego Ingardena zostały spisane w zawierającym 47 kartek zeszycie w szerokie linie, z wpiętymi dodatkowymi dwiema kartkami bez linii. Wyznaczono w nim marginesy, mocno zaginając wzdłuż wszystkie jego kartki. Na marginesach tych zapisano nieliczne uwagi oraz uzupełnienia do tekstu. Okładka nie zachowała się. Dwie ostatnie karty są luźne. W zeszycie znajdują się także dwie karty bez linii, pozbawione marginesu, na których zanotowano nie teksty protokołów, ale treści uzupełniające (krótkie fragmenty notatek, krótki słowniczek grecko-polski). Większość treści protokołów zapisano starannie piórem i dokonały tego różne osoby. Wyjątek stanowi tekst protokołu XIII z 28 kwietnia 1938 roku, znajdującego się na dwóch wpiętych kartkach, który został w około czterech piątych sporządzony na maszynie do pisania, następnie został dokończony odręcznie, piórem, wreszcie uzupełniony o odręcznie wpisane słowa alfabetem greckim. Naniesiono też na niego jedną uwagę ołówkiem. W większości tekstów protokołów wyróżniono podkreśleniem (pojedynczym lub podwójnym), ewentualnie odrębnym akapitem, daty poszczególnych seminariów. Nazwiska osób przemawiających na seminarium wielokrotnie zostały podkreślone pojedynczą linią w przeważającej ilości wypadków wypowiedzi wyróżniono odrębnym akapitem. Poszczególne osoby były tytułowane jako „P[an]” lub „P[ani]”, a także określane tytułem naukowym im przysługującym (doktor, profesor); w licznych wypadkach Romana Witolda Ingardena określano mianem „Pan Profesor", bez podawania nazwiska. Zapis grecki z reguły jest poprawny, $\mathrm{w}$ sytuacjach wątpliwych protokolanci niekiedy rezygnowali ze stawiania w nim akcentów.

Szesnaście zachowanych protokołów, jak ustalono na podstawie analizy duktów poszczególnych tekstów, zostało sporządzonych przez dziewięć osób. Tylko jedna podpisała się na dwóch sporządzonych przez siebie protokołach. Był to Bolesław Zieliński. Z pozostałych ośmiu osób udało się ustalić, na podstawie porównania stylów pisma w zachowanej korespondencji Romana Witolda Ingardena oraz protokołów innych jego seminariów, tożsamości kolejnych siedmiu. Należeli do nich: Władysław Bednarowski (protokoły I-IV oraz VI), Izydora Dąmbska (protokół V i VIII), Halina Korczyńska (protokół VII), Władysław Jaworski (protokoły X i XIV), Stefan Swieżawski (protokół XI), Bazyli Rudko (protokół XII) oraz Daniela Gromska (protokół XIII). Nie udało się ustalić, kim była osoba, która sporządziła protokół XV. Stwierdzono, że nie został on spisany ani pismem Ingardena, ani pismem jednego z aktywnych uczestników seminarium - Michała Zawadowskiego. Z powyższego zestawienia wynika, iż protokoły początkowe pod względem chronologicznym były przygotowywane przez Władysława Bednarowskiego. 
Fakt ten nie zaskakuje, jako że Bednarowski pełnił wówczas funkcję asystenta Oddziału II, kierowanego przez Romana Witolda Ingardena. Stopniowo jednak obowiązek spisywania protokołów przekazywano innym uczestnikom seminarium, głównie studentom, co także nie było praktyką niespotykaną w owym czasie. Interesujący natomiast jest fakt sporządzania protokołów przez dwie zasłużone już w środowisku filozoficznym Lwowa osoby posiadające stopień doktora: uczennice Kazimierza Twardowskiego - Danielę Gromską oraz Izydorę Dąmbską. Świadczy to o daleko posuniętym egalitaryzmie $\mathrm{w}$ ramach prowadzonego seminarium. Należy jednak zauważyć, że egalitaryzm ten nie dotyczył Ingardena. Jego pozycja na seminarium była szczególna - kierował on doborem omawianych zagadnień, dyskusja, w przypadkach spornych to do niego należało decydujące zdanie oraz nie sporządzał protokołów z posiedzeń.

Protokoły rejestrują etap formowania się lwowskiej szkoły ingardenowskiej. Pozycja Ingardena na Uniwersytecie Jana Kazimierza we Lwowie umocniła się w drugiej połowie lat trzydziestych XX wieku. Filozof był już wówczas zatrudniony jako profesor nadzwyczajny. Wystosowano też do Ministerstwa Wyznań Religijnych i Oświecenia Publicznego wniosek dotyczący jego „uzwyczajnienia”. Dlatego też dążył on do tego, by podobnie jak zmarły $\mathrm{w}$ trakcie tego samego roku akademickiego Kazimierz Twardowski stworzyć grono własnych uczniów i współpracowników. Pierwsze tego typu działania podjął Ingarden w trakcie przeprowadzania $\mathrm{w}$ poprzednich latach seminarium estetycznego. Seminarium arystotelesowskie miało być kolejnym etapem. Część osób - jak np. Władysław Bednarowski czy Michał Zawadowski - wzięła udział w obu cyklach zajęć, jednak spora grupa dotychczasowych uczestników seminarium Ingardena $\mathrm{z}$ różnych powodów $\mathrm{w}$ jego kontynuacji nie uczestniczyła. Na zajęciach zabrakło m.in. Leopolda Blausteina, Mariana Des Logesa, Ireny Krzemickiej (Krońskiej), Zofii Lissy, Henryka Mehlberga, Ostapa Ortwina, Stefanii Łobaczewskiej. Pojawiły się za to nowe twarze. Na podstawie tekstu protokołów, a także materiałów uzupełniających znajdujących się w tej samej jednostce archiwalnej w Archiwum Nauki Polskiej Akademii Nauk i Polskiej Akademii Umiejętności można zrekonstruować listę uczestników. Ostatecznie wśród osób, które wzięły udział lub chociaż zarejestrowały swój udział w seminarium arystotelesowskim, byli: Władysław Bednarowski, Janina Bladerówna, Ludwik Borkowski, Izydora Dąmbska, S. Eisenberg, Marek Fritzhand, Daniela Gromska, Władysław Jaworski, Maria Jędrzejewska, Kauferówna, Tadeusz Kohlmann, Halina Korczyńska, Seweryna Łuszczewska-Romahnowa, Bazyli Rudko, Zygmunt Rysiewicz, Helena Słoniewska, Stefan Swieżawski, Michał Zawadowski oraz Bolesław Zieliński.

Seminarium arystotelesowskie miało najwyższą rangę wśród prowadzonych przez Ingardena w roku akademickim 1937/1938 zajęć. Jego 
oficjalna nazwa to "Seminarium filozoficzne wyższe. Lektura wybranych rozdziałów Metafizyki Arystotelesa". Zajęcia były prowadzone w czwartki od godziny 18 i 20 . Odbywały się w sali posiedzeń seminarium filozoficznego, która znajdowała się na pierwszym piętrze "posejmowego" gmachu uniwersyteckiego przy ul. Marszałkowskiej $1^{2}$. Bodźcem do przeprowadzenia seminarium akurat o takiej tematyce był niewątpliwie fakt, iż Ingarden zobowiązał się do oceny przekładu Arystotelesowskiej Metafizyki, autorstwa Stanisława Lisieckiego ${ }^{3}$. Znalazł się w owym czasie w posiadaniu egzemplarza przygotowanego do druku tłumaczenia, który z inicjatywy Konstantego Michalskiego i Witolda Rubczyńskiego został mu przysłany z Krakowa ${ }^{4}$. Nie dziwi więc, że wśród wielu odniesień do wydań i przekładów Arystotelesowskich dzieł oraz literatury dotyczącej greckiego filozofa w protokołach seminaryjnych znajdują się, co prawda nieliczne, ślady odwoływania się do tekstu Lisieckiego.

Uczestnikom przyszło pracować w trudnych warunkach. Mimo płynących ze strony rządzącego obozu sanacyjnego kojących głosów dotyczących sytuacji międzynarodowej nad Polską zbierały się czarne chmury. Zarówno polityka Niemiec, nastawiona na odzyskanie utraconej traktatem wersalskim pozycji imperialnej, jak i Wielki Terror, trwający w bliskim Lwowowi ZSRR, nie mogły napawać optymizmem uczestników seminarium. Ingardenowska szkoła in statu nascendi, której kształtowanie się rejestrują protokoły seminarium arystotelesowskiego, ostatecznie została unicestwiona przez dwa totalitaryzmy w 1939 roku. Niektórzy uczestnicy tych zajęć zostali zamordowani, część po szeregu tragicznych wydarzeń znalazła się na emigracji, gdzie spędziła resztę swojego życia. Kilka osób związało się po wojnie z różnymi ośrodkami naukowymi w Polsce. W trudnych latach „powojnia" jedynie nieliczni mogli uczestniczyć w próbie budowania na nowo tego, co zniszczyli

2 Zob. Spis wykładów w roku akademickim 1937/38 [Uniwersytet Jana Kazimierza we Lwowie], Lwów 1937, 47.

3 O Stanisławie Lisieckim zob. Tomasz Mróz, Platon w Polsce 1800-1950. Typy recepcji - autorzy - problemy (Kęty: Wydawnictwo Marek Derewiecki, 2012), 280-303; tenże, "Zapomniany historyk filozofii starożytnej: Stanisław Lisiecki (1872-1960)", w: Rocznik Historii Filozofii Polskiej 6 (2013), 157-177; tenże, „Polish studies on Plato under the oppression of censorship: Lustosławski - Lisiecki - Witwicki", w: Censorship, Politics and Oppression, ed. by M. Maciejewska, W. Owczarski (Gdańsk-Sopot: Wydawnictwo Uniwersytetu Gdańskiego, 2018), 137-148.

4 Zob. list Zygmunta Zawirskiego do Romana Witolda Ingardena, Kraków, 25 listopada 1937 r., Archiwum Nauki Polskiej Akademii Nauk i Polskiej Akademii Umiejętności w Krakowie, sygn. K III-26: Roman Ingarden (kopia listu znajduje się w Archiwum Rodzinnym Ingardenów) oraz list Romana Witolda Ingardena do Konstantego Michalskiego, 7 lutego 1939 r. Archiwum Nauki Polskiej Akademii Nauk i Polskiej Akademii Umiejętności w Krakowie, sygn. K III-26: Roman Ingarden (odpis listu znajduje się w Archiwum Rodzinnym Ingardenów). 
agresorzy - szkoły ingardenowskiej, tym razem w Krakowie. Była to jednak już inna szkoła, tworzona w zmienionych warunkach, $\mathrm{z}$ inną pozycją Mistrza, z nowymi uczniami, w opozycji do tamtej filozofii ${ }^{5}$.

\section{Bibliografia}

Ingarden Roman Stanisław. 2000. Roman Witold Ingarden. Życie filozofa w okresie toruńskim (1921-1926). 24-27. Toruń: Wydawnictwo Uniwersytetu Mikołaja Kopernika.

Ingarden Roman Witold. 1999. „Dzieje mojej «kariery uniwersyteckiej»”, oprac. Ryszard Jadczak. Kwartalnik Filozoficzny 27, 2: 191.

Kuliniak Radosław, Pandura Mariusz. 2019. Jestem filozofem świata (Kó $\sigma \mu o v$

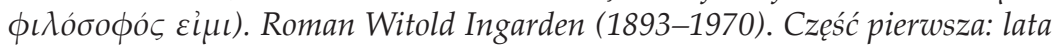
1893-1938. Kęty: Wydawnictwo Marek Derewiecki.

Kur Rafał. 2017. „Śladami przodków Romana Ingardena. Transkulturowa odyseja po ziemiach Europy Środkowej". Przegląd Filozoficzny. Nowa Seria 26, 2: 255-267.

List Zygmunta Zawirskiego do Romana Witolda Ingardena, Kraków, 25 listopada 1937 roku, Archiwum Nauki Polskiej Akademii Nauk i Polskiej Akademii Umiejętności w Krakowie, sygn. K III-26: Roman Ingarden (kopia listu znajduje się w ARI) oraz list Romana Witolda Ingardena do Konstantego Michalskiego, 7 lutego 1939 r., Archiwum Nauki Polskiej Akademii Nauk i Polskiej Akademii Umiejętności w Krakowie, sygn. K III-26: Roman Ingarden (odpis listu znajduje się w ARI).

Majewska Zofia. 1995. Ksiażeczka o Ingardenie. Szkic biograficzny. Lublin: Wydawnictwo Uniwersytetu Marii Curie-Skłodowskiej.

Majkowska Rita. 1999. „Roman Ingarden”. W: Przewodnik po zasobie Archiwum PAN, red. H. Krajewska, A. Kulecka. 368-369. Warszawa: Wydawnictwo Retro-Art.

Mróz Tomasz. 2012. Platon w Polsce 1800-1950. Typy recepcji - autorzy - problemy. 280-303. Kęty: Wydawnictwo Marek Derewiecki.

Mróz Tomasz. 2013. „Zapomniany historyk filozofii starożytnej: Stanisław Lisiecki (1872-1960)". Rocznik Historii Filozofii Polskiej 6: 157-177.

Mróz Tomasz. 2018. „Polish studies on Plato under the oppression of censorship: Lustosławski - Lisiecki - Witwicki". W: Censorship, Politics and Oppression, red. M. Maciejewska, W. Owczarski. 137-148. Gdańsk-Sopot: Wydawnictwo Uniwersytetu Gdańskiego.

Redzik Adam. 2015. ,"Zarys historii Uniwersytetu Jana Kazimierza (perspektywa ustrojowa i ogólnouniwersytecka)". W: Academia militans. Uniwer-

${ }^{5}$ Rozważania dotyczące seminarium arystotelesowskiego Romana Witolda Ingardena kontynowane są w przygotowanej do druku monografii: Radosław Kuliniak, Mariusz Pandura, Lwowskie seminarium arystotelesowskie Romana Witolda Ingardena $z$ lat 1937/1938, 220. 
sytet Jana Kazimierza we Lwowie, red. A. Redzik. 193-194. Kraków: Wydawnictwo Wysoki Zamek.

Spis wykładów w roku akademickim 1937/38. 1937. 47. Lwów: Uniwersytet Jana Kazimierza.

\section{Streszczenie}

Artykuł dotyczy problemu związanego z odczytaniem i prezentacją protokołów z seminarium arystotelesowskiego Romana Witolda Ingardena z roku 1937/1938. Przetrwały one w mieście nad Pełtwią II wojnę światową. W 1945 roku zostały wywiezione z miasta, podążając za filozofem, który już wówczas szukał swojego miejsca na jednej z polskich uczelni w Krakowie, a także we Wrocławiu. W okresie powojennym były przechowywane przez filozofa w jego mieszkaniu przy ulicy Biskupiej $14 \mathrm{w}$ Krakowie. Po śmierci Ingardena zostały przekazane przez rodzinę do ówczesnego Oddziału Archiwum Polskiej Akademii Nauk w Krakowie w jednej z transz, do których doszło w latach 1973-1992. Obecnie przechowywane są w Archiwum Nauki Polskiej Akademii Nauk i Polskiej Akademii Umiejętności w Krakowie w zbiorze K-III 26: Roman Ingarden, w dwuczęściowej jednostce 65, jako wydzielony podzbiór: 1937/38.

Słowa kluczowe: Roman Witold Ingarden, seminarium arystotelesowskie, protokoły.

\section{Summary}

The article deals with the problem of reading and presenting protocols from the Aristotelian seminar by Roman Witold Ingarden from 1937/1938. They survived World War II in the city spread along the Poltva River. In 1945, they were taken from the city by the philosopher who was already looking for a position at one of the Polish universities, in Krakow or in Wroclaw. In the post-war period, the documents were stored by the philosopher in his apartment at 14 Biskupia Street in Krakow. After Ingarden's death, they were transferred to the Archive Department of the Polish Academy of Sciences in Krakow by the family in one tranche, which took place in the years between 1973 and 1992. Currently, they are stored in the Archives of Sciences of the Polish Academy of Sciences and the Polish Academy of Arts and Sciences in Krakow in the K-III 26 collection: Roman Ingarden, in a two-part unit 65, as a separate subset: 1937/38.

Keywords: Roman Witold Ingarden, Aristotle seminar, protocols. 